\title{
Hubungan Pengetahuan Tentang Menopause Dengan Tingkat Kesiapan Menjelang Menopause Pada Ibu Premenopause
}

\author{
The Correlation of The Knowledge About Menopause With The \\ Readiness Ahead of Menopause For Premenopause Women \\ Agus Eka Nurma Yuneta ${ }^{a)}$, Hardiningsih ${ }^{\text {b) }}$, Fresthy Astrika Yunita ${ }^{\text {c) }}$ \\ ${ }^{a, b, c)}$ Prodi D3 Kebidanan, Sekolah Vokasi, Universitas Sebelas Maret, Jl. Ir. Sutami 36 A, \\ Kentingan Surakarta 57126 telp. (0271) 662622
}

korespondensi: ekayuneta@yahoo.com

\begin{abstract}
ABSTRAK
Latar belakang: Pada era globalisasi kesehatan menjadi hal yang sangat berharga, terutama pada kesehatan reproduksi yang sekarang ini menjadi perhatian dunia. Badan Pusat Statistik (BPS) di Indonesia menunjukkan 15,2\% dari 118 juta wanita Indonesia memasuki masa menopause. Berdasarkan survey awal terhadap 10 wanita pra menopause, hanya 2 orang mengetahui tanda gejala menopause.

Tujuan penelitian: Menganalisis hubungan pengetahuan tentang menopause dengan tingkat kesiapan menjelang menopause pada ibu premenopause.

Subjek dan Metode Penelitian: Jenis penelitian analitik kuantitatif dengan desain cross sectional. Penelitian dilakukan di RT 02 RW 23 Wonorejo, Karanganyar. Populasi penelitian adalah ibu premenopause anggota PKK Dahlia. Teknik sampling yang digunakan adalah simple random sampling. Jumlah sampel penelitian sebanyak $30 \mathrm{Ibu}$. Pengumpulan data dilakukan melalui pengisian kuisioner dan lembar observasi. Analisis data dilakukan secara komputerisasi menggunakan program SPSS 20.0 dengan uji statistik Chi-Square

Hasil Penelitian: Sebanyak 66.7\% (20 responden) memiliki pengetahuan tinggi menghadapi menopause dan sebanyak 60\% (18 responden) siap menghadapi menopause. Hasil uji statistik menggunakan chi-square didapatkan nilai $\mathrm{p}=0.045$ $(\mathrm{p}<0.05)$ yang berarti terdapat hubungan pengetahuan tentang menopause dengan tingkat kesiapan menjelang menopause pada ibu premenopause.

Kesimpulan: Terdapat hubungan pengetahuan tentang menopause dengan tingkat kesiapan menjelang menopause pada ibu premenopause.
\end{abstract}

Kata kunci: Pengetahuan, Kesiapan, Menopause. 


\begin{abstract}
Introduction: In this globalisation era, healthiness becomes a precious thing, especially on reproduction health that becomes worldwide attention. Statistics Indonesia (Badan Pusat Statistik (BPS) stated 15,2\% of 118 million women in Indonesia has entered the menopause period. According to the beginning survey of 10 premenopausal women, only 2 women knew menopause symptoms signs.

Purpose: To analyze the correlation of the knowledge about menopause with the readiness ahead of menopause for premenopausal women.

Subject and Method: The research was quantitative analytics with a crosssectional design. The research was located in RT 02 RW 23 Wonorejo, Karanganyar. The population of the research was premenopausal women of PKK Dahlia members. The research used simple random sampling with 30 women as the samples. The data was collected by questionnaire and observation sheet. Data analysis was carried out computerized using the SPSS 20.0 program with ChiSquare statistical test.

Results: There were $66,7 \%$ (20 respondents) that have high knowledge about facing menopause and there were 60\% (18 respondents) that ready to face menopause. The statistic test using chi-square resulted in $\mathrm{p}$-value $=0.045$ $(\mathrm{p}<0.05)$, which means there was a correlation of the knowledge about menopause with the readiness ahead of menopause for premenopausal women.

Conclusion: There was a correlation of the knowledge about menopause with the readiness of menopause for premenopausal women.
\end{abstract}

Keywords: Knowledge, Readiness, Menopause 


\section{PENDAHULUAN}

Satus kesehatan masyarakat selain ditunjukkan oleh angka kesakitan, angka kematian, dan membaiknya status gizi, juga ditunjukkan dengan adanya peningkatan Umur Harapan Hidup (UHH). Sejalan dengan meningkatnya taraf hidup dan pelayanan kesehatan manusia di Indoneisa membuat UHH meningkat. Kondisi ini membuat populasi orang berusia lanjut di Indonesia semakin tinggi $^{[1]}$. Meningkatnya UHH terutama pada perempuan, mendorong kebijakan terhadap penduduk usia tua, bertambahnya jumlah penduduk tua dapat dimaknai sebagai tingkat kesejahteraan, meningkatnya kondisi kesehatan tetapi juga dapat dimaknai sebagai beban karena kelompok usia tua ini sudah tidak produktif lagi ${ }^{[2]}$. Seiring dengan peningkatan UHH, maka akan akan terjadi peningkatan penyakit-penyakit tua, khususnya pada wanita. Kejadian penyakit usia tua ini dihubungkan dengan penurunan kadar hormon estrogen. Penurunan hormon ini telah dimulai sejak usia 40 tahun $^{[3]}$.

Berdasarkan data statistik dari Departemen Kesehatan pada tahun 2015, jumlah penduduk Indonesia mencapai 255 juta dan terjadi peningkatan menjadi 268 juta pada tahun $2019^{[4]}$. Tahun 2000 jumlah penduduk wanita berusia 50 tahun telah mencapai 15,5 juta orang dan diperkirakan pada tahun 2025 jumlah perempuan hidup dalam usia menopause tersebut terus bertambah jumlahnya menjadi 60 juta tentunya hal ini perlu mendapatkan perhatian bagaimana kesehatan reproduksinya karena pada masa ini akan terjadi perubahan fisik dan psikologis yang dapat menimbulkan berbagai macam keluhan pada kesehatan. Wanita Indonesia yang memasuki masa premenopause saat ini sebanyak $7,4 \%$ dari populasi. Jumlah tersebut diperkirakan menjadi $11 \%$ pada 2005, kemudian naik lagi sebesar 14\% pada tahun 2015. Di Indonesia data Badan Pusat Statistik menunjukkan $15,2 \%$ juta wanita memasuki masa menopause dari 118 juta wanita Indonesia ${ }^{[5]}$.

Sindrom pre menopause dialami oleh banyak wanita hampir di seluruh dunia, sekitar 70-80\% wanita Eropa, $60 \%$ di Amerika, 57\% di Malaysia, $18 \%$ di Cina, dan $10 \%$ di Jepang serta Indonesia. Dari beberapa data tampak bahwa salah satu faktor dari perbedaan jumlah tersebut adalah karena pola makan. Wanita Eropa dan Amerika mempunyai estrogen yang lebih banyak dari Asia. Penurunan kadar estrogen tersebut sering menimbulkan gejala yang sangat mengganggu aktivitas kehidupan para wanita ${ }^{[3]}$.

Gejala yang menyertai sindrom pre menopause yang meliputi hot flushes (rasa panas dari dada hingga wajah), night sweat (berkeringat di malam hari), vaginal dryness (kekeringan vagina), penurunan daya ingat, insomnia, depresi, fatique (mudah capek), penurunan libido, dyspareunia (rasa sakit ketika berhubungan seksual), dan incontinence urinary (beser) ${ }^{[3]}$. Menopause ini terjadi pada perempuan pada akhir masa siklus haid yang terakhir, namun kepastiannya apabila perempuan sudah tidak lagi mengalami siklus haid selama paling kurang 12 bulan. Karena itu menopause ini mulai terjadi pada rata-rata umur 50 tahun, tetapi bisa juga terjadi secara normal pada wanita yang berusia diatas atau dibawah usia 50 tahun $^{[6]}$. 
Berdasarkan data SDKI tahun 2012 jumlah persentase menopause menurut umur 30-34 tahun sebanyak $11,4 \%, 35-39$ tahun sebanyak $13,6 \%$, 40-41 tahun sebanyak $14,8 \%, 42-43$ tahun sebanyak 17,8\%, 44-45 tahun sebanyak 22,6\%, 46-47 tahun sebanyak 32,6\%, 48-49 tahun sebanyak44,0\%. ${ }^{[6]}$.

Studi pendahuluan dari 10 perempuan hanya ada 2 yang mengetahui tentang persiapan menopause. Berdasarkan latar belakang diatas maka peneliti tertarik untuk meneliti tentang Hubungan Pengetahuan tentang Menopause dengan Tingkat Kesiapan Menjelang Menopause pada Ibu Premenopause di Desa Wonorejo Kabupaten Karanganyar.

\section{SUBJEK DAN METODE}

Jenis penelitian ini merupakan penelitian analitik observasional. Desain penelitian yang digunakan adalah cross sectional untuk mengetahui hubungan pengetahuan tentang menopause dengan tingkat kesiapan menjelang menopause pada ibu premenopause.

Lokasi penelitian di RT 02 RW 23 Wonorejo, Karanganyar yang dilakukan selama 6 (enam) bulan. Populasi penelitian yaitu semua ibu premenopause anggota PKK Dahlia. Teknik sampling yang digunakan adalah simple random sampling dengan jumlah sampel sebanyak $30 \mathrm{ibu}$.

Alat ukur dalam penelitian ini yaitu kuesioner yang dilakukan secara langsung pada ibu menopause meliputi identitas dan pengetahuan ibu. Sedangkan untuk menentukan kesiapan ibu alat ukur yang digunakan adalah lembar observasi. Analisis data dilakukan secara komputerisasi menggunakan program SPSS 20.0 dengan uji statistik Chi-Square.

\section{HASIL}

Bab ini menyajikan hasil penelitian dengan menggunakan analisis univariat dan analisis bivariat terhadap variabel pengetahuan tentang menopause dan kesiapan menjelang menopause.

a. Hasil Analisis Univariat

Tabel 1. Pengetahuan tentang Menopause

\begin{tabular}{lcc}
\hline Variabel & $\mathbf{N}$ & $\boldsymbol{\%}$ \\
\hline Tinggi & 20 & 66,7 \\
Rendah & 10 & 33,3 \\
Total & 30 & 100 \\
\hline
\end{tabular}

Tabel 1 menunjukkan bahwa mayoritas responden memiliki pengetahuan tinggi tentang menopause yaitu sebanyak 20 responden $(66.7 \%)$, sedangkan responden yang pengetahuan rendah tentang menopause sebanyak 10 responden $(33,3 \%)$.

Tabel 2. Tingkat Kesiapan Menjelang Menopause

\begin{tabular}{lcc} 
Variabel & N & \% \\
\hline Siap & 18 & 60,0 \\
Tidak Siap & 12 & 40,0 \\
Total & 30 & 100 \\
\hline
\end{tabular}

Tabel 2 menunjukkan bahwa mayoritas responden yang siap menghadapi menopause yaitu sebesar 18 responden (60\%), selanjutnya responden yang tidak siap menghadapi menopause sebanyak 12 responden (40\%). 
b. Hasil Analisis Bivariat

Tabel 3. Hasil Uji Statistik ChiSquare

\begin{tabular}{lccc}
\hline & value & df & $\begin{array}{c}\text { Asymp.Sig } \\
\text { (2-Sided) }\end{array}$ \\
\hline Pearson & 203.571 & 171 & 0.045 \\
$\begin{array}{l}\text { Likelihood } \\
\text { Ratio }\end{array}$ & 110.600 & 171 & \\
$\begin{array}{l}\text { Linear-by- } \\
\text { Linear }\end{array}$ & 12.936 & 1 & .000 \\
$\begin{array}{l}\text { Assosiation } \\
\text { N of Valid } \\
\text { Cases }\end{array}$ & 30 & & \\
\hline
\end{tabular}

Tabel 3 menunjukkan bahwa terdapat hubungan pengetahuan tentang menopause dengan tingkat kesiapan menjelang menopause pada ibu premenopause dengan nilai $p<0.050$ yaitu $p=0,45$.

$\frac{\text { PEMBAHASAN }}{\text { Pembahasan berisi hasil penelitian }}$

Pembahasan berisi hasil penelitian yang telah peneliti laksanakan sesuai dengan langkah penelitian yang ada serta menghubungkan teori dan temuan penelitian sebelumnya baik dari jurnal maupun sumber relevan lainnya. Hasil penelitian ini menunjukkan bahwa terdapat hubungan positif pengetahuan menghadapi menopause dengan kesiapan $(p=0.045)$. Selanjutnya, peneliti akan membahas hasil penelitian dengan ulasan yang lebih rinci sebagai berikut.

Penelitian ini sejalan dengan Indah et al. bahwa pengetahuan memiliki hubungan dengan kesiapan ibu menghadapi menopause ${ }^{[7]}$. Penelitian lain yang mendukung hasil penelitian ini adalah Sasrawita ${ }^{[8]}$ yang menunjukkan bahwa terdapat hubungan yang signifikan antara pengetahuan ibu pramenopause dengan kesiapan menghadapi masa menopause. Moshki et al. menemukan bahwa program edukasi masa premenopause dapat meningkatkan efikasi diri dan penerimaan diri pada masa menopause $^{[9]}$. Di samping itu, pada kelompok intervensi diketahui terdapat peningkatan sikap menghadapi menopause, peningkatan sikap pada kelompok intervensi dikaitkan dengan adanya peningkatan pengetahuan tentang perilaku menghadapi menopause dan pengalaman positif yang didapatkan setelah simulasi keterampilan menghadapi permasalahan yang ditemui pada masa menopause.

Pengetahuan salah satunya didukung oleh pendidikan, pendidikan yang memadai akan memudahkan seseorang memperoleh pemahaman yang lebih baik tentang menopause. Pemahaman yang baik tentang seluk beluk menopause akan menunjang kesiapan wanita dalam menghadapi menopause. Tingkat pendidikan yang baik akan memengaruhi seseorang dalam pengembangan nalar dan analisa. Dengan daya nalar yang baik akan memudahkan untuk meningkatkan pengetahuan, salah satu cara yang baik dalam rangka memberikan informasi dan pesan kesehatan ${ }^{[5]}$.

Pengetahuan tentang menopause memiliki peran penting pada masa menopause, karena dengan pengetahuan yang tinggi maka akan dapat meningkatkan kemampuan perempuan dalam menghadapi dan mengelola menopause $^{[10]}$. Memon et ai. menemukan bahwa sebanyak $87 \%$ perempuan yang memiliki pengetahuan tinggi akan memiliki persepsi positif terhadap menopause dan $76 \%$ merasakan hidup yang lebih tenang dan mudah ketika menghadapi menopause ${ }^{[11]}$. Pada perempuan yang memiliki pengetahuan rendah akan cenderung memiliki persepsi negatif terhadap 
menopause dan merasa pemarah, mudah tersinggung, memengaruhi kemampuan bekerja, serta kehilangan feminitas selama menghadapi masa menopause. Hal ini didukung oleh Monica yang dalam penelitiannya menemukan bahwa pendidikan kesehatan tentang menopause secara intensif sebanyak dua kali atau lebih dapat meningkatkan sikap ibu dalam menghadapi menopause ${ }^{[12]}$.

Pada penelitian ini diketahui bahwa ada hubungan sikap ibu premenopause terhadap kesiapan menghadapi menopause dikarenakan tingkat pendidikan dan pekerjaan sehingga mempengaruhi sikap responden terhadap perubahan pada masa menopause. Sikap positif dari ibu yang akan menghadapi menopause mampu mengalihkan perasaan yang tidak menyenangkan ke hal-hal positif pula dengan cara melakukan aktivitas yang berguna. Penerimaan yang positif terhadap masa menopause sebagai upaya mempersiapkan diri secara fisik dan psikis sejak dini.

Distribusi frekuensi kesiapan menopause menunjukkan distribusi tertinggi adalah siap yaitu sebanyak 35 responden $(65 \%)$. Kesiapan ibu terhadap pra menopause merupakan kondisi ibu untuk mempersiapkan diri baik psikologis maupun fisik dalam menghadapi masa menopause.

Beberapa faktor yang berhubungan dengan kesiapan menopause pada wanita antara lain tingkat pendidikan responden. Tingkat pendidikan responden menunjukkan distribusi tertinggi adalah lulus SMA/sederajat. Hal ini sebagaimana dikemukakan oleh Notoatmodjo bahwa tingkat pendidikan merupakan salah satu faktor yang mempengaruhi tingkat pengetahuan, sehingga dapat berpengaruh terhadap besar kecilnya kesiapan ibu dalam menghadapi menopause $^{[13]}$. Ibu yang memiliki pengetahuan kesehatan lebih baik akan lebih siap dalam menghadapi menopause sehingga terjadi perubahan yang baik atau positif. Pengetahuan yang baik membantu ibu memahami dan mempersiapkan dirinya menjalani menopause.

\begin{tabular}{l}
\hline KESIMPULAN \\
\hline Mayoritas pengetahuan ibu \\
mengenai menopause yaitu sebesar \\
$66,7 \%$ (20 responden) dan mayoritas \\
ibu yang siap menghadapi \\
menopause yaitu sebesar 60\% (18 \\
responden). Dari hasil uji statistik uji \\
Chi-Square diperoleh nilai $p=0.045$ \\
yang berarti terdapat hubungan \\
antara pengetahuan dengan kesiapan \\
menghadapi menopauase. \\
Pengetahuan yang baik membantu \\
ibu memahami dan mempersiapkan \\
dirinya menjalani menopause.
\end{tabular}

\section{DAFTAR PUSTAKA}

1. Ismiyati, A. (2010). Hubungan Tingkat Pengetahuan Tentang Menopause Dengan Kesiapan Menghadapi Menopause Pada Ibu Premenopause Di Perumahan Sewon Asri Yogyakarta. Naskah Publikasi, Program Studi D IV Kebidanan Trasnfer Universitas Sebelas Maret. Surakarta

2. Kementerian Kesehatan RI. (2015). Profil Kesehatan Indonesia 2014. Kementerian Kesehatan Republik Indonesia (Vol. 51). https://doi.org/10.1037/00223514.51.6.1173

3. Proverawati, Atikah, dan Sulistyawati, E. (2010). Menopouse dan Sindrom Premenopause.Yogyakarta: 
Numed.

4. Badan Pusat Statistik. 2015. http://bps.go.id. Diakses pada tanggal 13 Juli 2021 pada pukul 11.00 WIB.

5. Rasyid, E. P., Yusuf, Z. K., Djunaid, R., Studi, P., Keperawatan, I., Keperawatan, J., \& Gorontalo, U. N. (2014). Kata Kunci: Pengetahuan, Sikap, Kecemasan, Menopause 1. universitas gorontalo. Retrieved from https://www.google.com/search? $\mathrm{q}=$ PRIFIL+KESEHATAN+IND ONESIA+2014\&ie =utf-

$8 \&$ oe $=$ utf $-8 \&$ client $=$ firefox $\mathrm{b} \# \mathrm{q}=$ skripsi+eka+putriyanti\&Mu lyani, S. (2013). Menopause Akhir Siklus Menstruasi Pada Wanita di Usia Pertengahan.

6. Badan Pusat Statistik (BPS). (2013). Survei Demografi dan Kesehatan Indonesia 2012. https://kesra.jatengprov.go.id/file $\% 20$ pdf/sdki2012.pdf

7. Indah, R. A., Purwanti, Y., dan Sarwinanti. (2018). Hubungan Pengetahuan dengan Kesiapan Ibu dalam Menghadapi Menopause di Dusun Krandon Malangan.

http://digilib2.unisayogya.ac.id/x mlui/handle/123456789/1366

8. Sasrawita. (2017). Hubungan Pengetahuan, Sikap tentang Menopause dengan Kesiapan Menghadapi Menopause di Puskesmas Pekanbaru. Journal Endurance 2(2) June 2017 (117123).

DOI: http://doi.org/10.22216/jen.v2i2. 1853

9. Moshki, M., Mohammadzadeh, F., \& Dehnoalian, A. (2017). The effectiveness of a group-based educational program on the selfefficacy and self-acceptance of menopausal women: A randomized controlled trial. Journal of Women \& Aging, 30(4), $\quad 310$ 325. doi:10.1080/08952841.2017 .1366753

10. Eun Kyung, K ., Hyun Soon., P., dan Nam Mi, K. (2014). Menopause Knowledge, Attitude, Symptom and Management among Midlife Employed Women. Journal of Menopausal Medicine 2014;20:118-125. http://dx.doi.org/10.6118/jmm.20 14.20.3.118

11. Memon FR, Jonker L, Qazi RA. Knowledge, attitudes and perceptions towards menopause among highly educated Asian women in their midlife. Post Reproductive Health. 2014;20(4):138-142. doi:10.1177/2053369114557510

12. Monica, L.P. (2018). The Effectiveness of Health Education ti the Women's Attitute in Facing PreMenopause. Jurnal Ners dan Kebidanan. Vol. 5, No. 1, April 2018.

DOI: 10.26699/jnk.v5i1.ART.p0 79-082

13. Notoatmodjo, S. (2007). Pendidikan dan Perilaku Kesehatan. Jakarta: Rineka Cipta 